\title{
High-level Professional Construction and Reform Ideas
}

\author{
Ping Xin ${ }^{1, a}$, Dandan $\mathrm{Ma}^{1, \mathrm{~b}^{*}}$ and Hongtao $\mathrm{Mi}^{1, \mathrm{c}}$ \\ ${ }^{1}$ BeiHua University, Jilin City Longtan Hill Street No. 1, JiLin, China \\ a359411897@qq.com, b¹14614215@qq.com, '8158161@qq.com
}

\begin{abstract}
Keywords: High-level Professional; Teaching management; Curriculum system reform; Reform in Education
\end{abstract}

\begin{abstract}
Under the background of new economy and new industries, colleges and universities should set the new concept of, build the new structure of the innovative, integrated, full-cycle engineering education, explore and implement the new model of emerging engineering and traditional engineering combined disciplines, guarantee the new quality of the international competitive engineering education, establish and perfect the new system of the Chinese characteristics engineering education.
\end{abstract}

\section{Introduction}

Chinese new generation of the electric power equipment, the advanced CNC machine tools, robots and new materials will become the majors which have the largest talent gap. The talent gap of electric power equipment is reaching 2.5 million. It is estimated that by 2025 , the talent gap of electric power equipment will reach 9 million. Talent shortage will not only occur in the future, but also at present. Currently, there is a shortage of talent in new economic areas, such as big data, internet of things, artificial intelligence, network security and comprehensive health. A new round of technological revolution and industrial change is now accelerating in the world, and the competition of the comprehensive national strength is becoming more and more intense. China implements many significant strategies, including 'Innovation-driven Development Strategy', 'China Manufacturing 2025', 'Internet plus' and 'The Belt and Road'. New economy characterized by new technologies, new formats and new industries is advancing vibrantly, which requires that engineering and technological talent should equip with innovative entrepreneurial capacity and cross-border integration capacity.

\section{Professional Training Objectives}

Based on the principle of 'Face the social needs, grasp the frontier, highlight the advantages, strengthen the characteristics', We will combine the traditional electrical engineering and information technology with automation or other professional, in order to promote the traditional professional transformation and the construction of new engineering profession. Insist on combining the theoretical research with the engineering application research and strengthen the base construction and team building so that improve the ability of undertaking significant scientific research projects and technical breakthrough, improve the innovation ability of scientific theory and technology. Cultivating the advanced practice-oriented talents who meet the needs of the socialist modernization, are well developed morally, intellectually and physically, are equipped with basic knowledge of engineering technology, teamwork ability, international vision and engineering system innovation ability and the comprehensive quality of surviving and growing in the modern engineering environment.

\section{Overall Goals and Ideas of Professional Construction}

The goal of the professional construction is to cultivate the advanced practice-oriented talents with multidisciplinary cross, scientific research innovation ability and practice innovation ability. Construct electrical engineering and automation into a high-level profession, which has advanced 
educational philosophy, breakthrough in reform and innovation, high quality of personnel training, significant social service effectiveness and strong influence. Form professional construction reference norms with demonstration significance, easy transplant and promotion from the perspective of system engineering.

Cross-integrate the emerging professions, such as electrical engineering and automation, electronic information, communication engineering, information engineering. Combine with the new needs of the social development, the new trend of professional integration, the new achievements in scientific research. Expand the connotation and construction focus of traditional professions, format a new curriculum system, create an upgraded version of the traditional professions, transform and upgrade service industry, develop to the high end of the value chain.

In order to achieve the above goals, we will carry out our work in the educational philosophy update, institutional innovation, operational mechanism innovation and so on. To achieve the goal of 'promote development with characteristics' and Make it a demonstration.

\section{The Implementation and Effect of Existing Personnel Training Program}

The professional training program closely revolve around the basic issues and the main development line, focusing on the basic theoretical knowledge, the internal law of the development and the basic skills of teaching. Target at cultivating the applied talent, focus on innovation and personalization training. Stimulate students' learning abilities and interest through scientific and technological innovation and subject competition, so that students have the ability to work independently and learn lifelong to meet the needs of advanced applied talent.

\section{The Plans and Reasons for Further Modification}

The training program and the training mode will lead to the shortage of engineering practice ability, weak engineering innovation consciousness, narrow professional knowledge, graduates employment difficulties, which can not satisfy the needs of the new economy, the new normal engineering jobs.

The principle is being conducive to the cross-integration of multidisciplinary, improving the quality of personnel training, satisfying students' personalized needs, and the social adaptability of personnel. According to the principle, we revise the training program of talent, lay emphasis on the mutual penetration and integration of electrical information, strengthen the connections between courses, improve the degree of integration and modularization, transform and expand the traditional professions, and develop a number of new engineering profession.

Teaching Content and Curriculum System Reform. Set social needs as the guide, optimize the training program, build capacity training curriculum system. Make full use of information technology, for the actual object of the project for the cross-integration of the course group. Organically integrated the theoretical teaching and practical teaching. Construct the network core series of courses of facing the engineering education for cultivating the actual engineering capacity. Lay emphasis on cultivating the organic combination ability of curriculum with engineering object. The goal is the seamless connection between graduation and the enterprise needs.

A multi-level personalized three-dimensional practical and teaching system is as shown in Fig.1. 

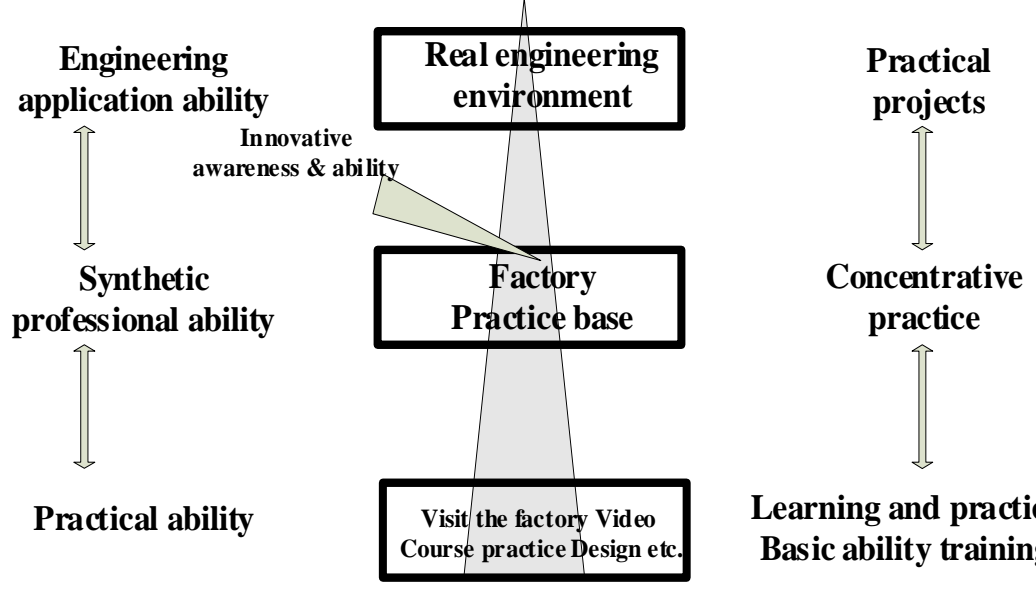

Learning and practice Basic ability training

Figure 1. Multi-level personalized three-dimensional system

The Ideas and Goals of Teaching Materials Construction and Teaching Facilities. Based on the development of disciplines, serve the new economic needs for the purpose, update the teaching content, construct the practice base of cross-integrate information technology, publish teaching materials of characteristics. Timely adjust the teaching content, select traditional content, add new knowledge, new technologies, new results and so on, in order to ensure that students' knowledge system and ability adapt to the social needs and lay the foundation for high-level employment. In the next five years, four teaching materials of cross-integrate characteristics is to publish. Establish the laboratory making use of information technology to development virtual factory, the workshop, and the experimental platform. Construct provincial virtual simulation laboratory. Add three new training base in school. Introduce two tripartite training institutions to participate in school teaching. Strive to build a national experimental demonstration teaching center.

The Goal of Teaching Management. Improve the teaching management, inspection and supervision. Format the double closed-loop multi-element collaborative the talent quality evaluation system combining the teaching evaluation in school and outside unit. Establish a set of quality assurance system, which asks the undergraduate teaching quality assurance system elements and procedures for the main line, teaching quality monitoring and assurance measures for the main content, the academic department for the main organization, implement by the joint of education department and the Department. Content covers that adjust and determine the goal of personnel training according to the needs of talents. According to the requirements of post and post groups, make the personnel training programs, construct the talent knowledge and ability quality structure, and implement of daily teaching works and so on.

The Measures of Teaching Content and the Curriculum System Reform. System integration and optimization of professional curriculum system is to improve students' learning efficiency and effectiveness. It also can cultivate the critical thinking, design thinking, engineering thinking, management thinking, engineering ethics, and cross-cultural communication capacity. Make teaching content, establish curriculum system, continue to deepen the self-development engineering education concept of professional cross-integration, create a series of courses to meet the needs of engineering education, and set up innovative entrepreneurship courses which satisfying the needs of the engineering education, such as training in entrepreneurial ability, innovative guiding methods and ability, project management and innovation practice. Put the design, learning, management, practice, improvement, implementation and operation of the elements throughout the teaching process to improve the students' rapid adaptability. Take the 'ternary education' of colleges and universities, enterprises and social training institutions so that students can quickly adapt to the needs of the posts. 


\section{Acknowledgements}

This research was financially supported by the Education Department Project of Jilin Province [SGJY201606] and [2016] 56nd, Education and teaching research topics of Beihua University [XJQN2017030], Innovation and entrepreneurship projects of College Students [201510201011].

\section{References}

[1] A. J. Basin, A. A. Hakim, Curriculum assessment as a direct tool in ABET outcomes assessment in a chemical programmer, European Journal of Engineering Education, vol. 15, 2016, pp. 489-505.

[2] R. Pert ova, A. Tiebreak, T. M. Sob, An Electronic Web based Assessment System, Journal of STEM Education, Vol.7, 2015, pp. 44-57.

[3] Z. J. Wu, J. Q. Li, C. L. Huang, Adhere to the five attention, promote the five changes, cultivating engineering excellence, Higher engineering education research, Vol. 15, 2013, pp. 489-505.

[4] F. M. Kong, such as the construction of road of the applied university, Peking University press, China 2006.

[5] Y. M. Sun, L. Guo, About planar affine nonlinear system of global asymptotic controllability, Chinese science, Vol. 35, 2013, pp. 830-839.

[6] D. Z. Cheng, Controllability of Switched Bilinear Systems, IEEE Trans. on Automatic Control, Vol.50, 2005, pp. 511-515.

[7] D. Z. Cheng, R. Ortega, E. Panatela, On port controlled Hamiltonian systems, In Advanced Robust and Adaptive Control -Theory and Applications, Vol. 10, 2015, pp. 3-16.

[8] H. X. Yang, Reform of personnel training mode: a report on the pilot reform of the national educational system, Research on Higher Education in China, Vol. 10, 2014, pp. 35-39.

[9] W. Zhang, Y. L Du, The realistic reflection and contemporary innovation of talent cultivation model, educational research, Vol. 01, 2015, pp. 122-127.

[10] Y. Zhang, Y. T. Zhang, Guided by the third industrial revolution: the strategic choice for the development of Higher Engineering Education in China, Education research, Vol. 5, 2014, pp. 47-52.

[11]H. Q. Zhu, The essence and evaluation of Educational Modernization: what kind of educational modernization we need to study, Education Research, Vol. 15, 2013, pp. 50-55.

[12] Wu Z J, Li J Q, Huang C L, adhere to the five attention, promote the five changes, cultivating engineering excellence, higher engineering education research, Vol. 15, 2013, pp. 86-90. 